\title{
Representações Sociais sobre o Corpo e Satisfação Sexual de Mulheres Mastectomizadas e seus Parceiros
}

\author{
Tamiris Molina Ramalho Hirschle ${ }^{1, *}$ \\ Orcid.org/0000-0002-7456-1025 \\ Silvana Carneiro Maciel $^{1}$ \\ Orcid.org/0000-0003-1489-1126 \\ Geane Karla de Amorim ${ }^{1}$ \\ Orcid.org/0000-0001-7190-0813
}

${ }^{1}$ Universidade Federal da Paraíba, João Pessoa, PB, Brazil

\begin{abstract}
Resumo
Mulheres que passam pelo procedimento da mastectomia e seus parceiros se deparam com o corpo transformado que remete a diversas implicações incluindo a satisfação sexual. Este trabalho objetiva compreender as representações sociais acerca do corpo da mulher e do corpo mastectomizado e o nível de satisfação sexual dos casais. Participaram do estudo 10 díades (mulheres mastectomizadas e seus parceiros) e utilizou-se como instrumento uma escala de satisfação sexual e a Técnica de Associação Livre de Palavras com os estímulos corpo da mulher e corpo da mulher mastectomizada. Observou-se que o corpo mastectomizado possuiu mais representações negativas vinculadas à aparência da mama, impactando no nível de satisfação sexual do casal, onde se constatou que este diminui após a mastectomia, interferindo na autoimagem e na vida conjugal. Destaca-se a necessidade de ampliação de políticas públicas voltadas para essa população visando a cirurgias reparadoras e ao trabalho com as representações sociais visando redimensionamento da sexualização das mamas impactando na melhoria da qualidade de vida dessas mulheres e de seus parceiros.
\end{abstract}

Palavras-chave: Representações sociais, mulheres mastectomizadas, satisfação sexual.

\section{Social Representations of the Body and Sexual Satisfaction in Mastecomized Women and their Partners}

\begin{abstract}
Women who undergo mastectomy and their partners face a transformed body, which has several implications, including an effect on their sexual satisfaction. The aims of the present study were to understand the social representations of the female body, the social representations of the mastectomized body, and the level of sexual satisfaction of these couples. Ten couples (mastectomized women and their partners) were included in the study. The study instruments were a scale of sexual satisfaction and the free word association technique (FWAT), using the expressions "female body" and "mastectomized female body" as stimuli. The mastectomized body was observed to have more negative representations related to the
\end{abstract}

Endereço para correspondência: Avenida Manoel Deodato, nº 821, Apto 203-A, Bairro Torre, João Pessoa, PB, Brasil 58040-181. E-mail: tami.ramalho@gmail.com

Apoio: Coordenação de Aperfeiçoamento de Pessoal de Nível Superior (CAPES). 
appearance of the breast(s). Couples' sexual satisfaction decreased after mastectomy, interfering with the women's self-image and with marital life. The need to expand public policies targeting this population is emphasized, with a focus on reconstructive surgery and work with social representations to revise the sexualization of breasts. Such policies can improve quality of life for mastectomized women and their partners.

Keywords: Social representations, mastectomized women, sexual satisfaction.

\section{Representaciones Sociales sobre el Cuerpo y Satisfacción Sexual de Mujeres Mastectomizadas y sus Parejas}

\section{Resumen}

Tanto las mujeres que han sido sometidas a mastectomía como sus parejas se encuentran ante un cuerpo trasformado el cual remite a diversas implicaciones, entre otras; la satisfacción sexual. El objetivo de este trabajo estriba en comprender las representaciones sociales del cuerpo de la mujer y del cuerpo mastectomizado y ahondar en el nivel de satisfacción sexual de estas parejas. En el estudio han participado 10 matrimonios (mujeres mastectomizadas y sus parejas) y los instrumentos utilizados han sido una escala de satisfacción sexual y la Técnica de Asociación Libre de Palabras con los estímulos cuerpo de la mujer y cuerpo de la mujer mastectomizada. Hemos observado que el cuerpo mastectomizado obtuvo más representaciones negativas vinculadas a la apariencia de la mama, interviniendo en el nivel de satisfacción sexual del matrimonio, donde se constató que este disminuye después de la mastectomía, perjudicando la autoimagen y la vida en pareja. Se destaca la necesidad de la ampliación de políticas públicas volcadas para esta población hacia las cirugías restauradoras y al trabajo con las representaciones sociales con vistas al redimensionamiento de la sexualización de las mamas con el objetivo de mejorar la calidad de vida de estas mujeres y de sus parejas.

Palabras clave: Representaciones sociales, mujeres mastectomizadas, satisfacción sexual.

O câncer de mama é o tipo de câncer que mais acomete as mulheres em todo o mundo; 1,67 milhões de casos novos dessa neoplasia foram esperados para o ano de 2012, em todo o mundo, o que representa $25 \%$ de todos os tipos de câncer diagnosticados nas mulheres, com cerca de 520 mil mortes estimadas para o ano de 2012. É a segunda causa de morte por câncer nos países desenvolvidos, atrás somente do câncer de pulmão, e a maior causa de morte por câncer nos países emergentes (Instituto Nacional de Câncer [INCA], 2014).

Como tratamento primário, geralmente, realiza-se a intervenção cirúrgica que pode ser restrita ao tumor, atingir tecidos circundantes ou até a retirada total da mama (mastectomia radical) e também a retirada dos linfonodos da região axilar e dos músculos peitorais. Além disso, a mulher pode ser submetida a outros tratamentos como a quimioterapia, radioterapia e hormonio- terapia (Cesnik \& Santos, 2012; Santos \& Vieira, 2011).

A expressão câncer carrega um estigma forte, pois, em geral as pessoas logo o associam com a morte; no caso das mulheres, o câncer de mama ainda é mais temido pelo fato adicional de acometer uma parte valorizada do corpo dessas mulheres que em muitas culturas desempenha uma função significativa para sua sexualidade e identidade feminina (Silva et al., 2012).

A mama é vista, na atual sociedade, como um símbolo corpóreo da sexualidade, feminilidade e ligada à construção da identidade da mulher, o que leva a pensar que qualquer patologia que ameace este órgão leva a uma perda da autoestima e alteração na sua autoimagem, acarretando sentimentos de inferioridade e rejeição (Seara, Vieira, \& Pechorro, 2012). Nesse sentido, quando a mulher tem que submeter-se à mastectomia, a qual provoca uma alteração evi- 
dente no contorno do corpo, esse processo pode ser ainda mais difícil, pois tal alteração ocasiona sentimentos de estranheza, sofrimento e autodepreciação provocados pela não aceitação da perda da mama; de forma que a compreensão de tais reações deve levar em conta o componente simbólico ligado às mamas, relacionado à maternidade, à fertilidade, à reprodução e à sexualidade (Angerami, 2013; Santos, Dias, Lacerda, Barreto, \& Santos, 2008). É possível, pois, perceber que, no plano das representações, a mama costuma ser associada a atos prazerosos, não combinando, portanto, com a ideia de ser objeto de uma intervenção médica dolorosa e mutiladora. Do ponto de vista da mulher acometida, a possibilidade de desenvolver uma doença na mama pode comprometer o processo de construção feminina da sua autoimagem e da efetivação da sua sexualidade (Scorsolini-Comin, dos Santos, \& Souza, 2009).

Algumas mulheres acometidas pelo câncer de mama tendem a perceber e representar seus corpos como mutilados, veem-se como monstros, anormais e deficientes, elas passam a se ver como se não fossem mais bonitas e perdessem a sua feminilidade. Além disso, o câncer de mama imputa na sua portadora um estigma social que abala sua imagem corporal, as interações sociais e por vezes o relacionamento com seu parceiro conjugal, pois muitas relatam sofrer rejeição sexual por parte dos parceiros, o que pode afetar a sua satisfação sexual (Silva et al., 2012).

A sexualidade é parte integrante da constituição da experiência humana, abrangendo os sentimentos mais íntimos de individualidade; ela existe em todas as interações e contextos e se relaciona diretamente com o nosso bem-estar e a experiência de nós mesmos como seres sexuais. Assim, torna-se claro que a sexualidade não é um conceito que pode ser considerado separado da saúde; pois é de fato fundamental para o bem-estar e formação do autoconceito das pessoas (Santos, 2012; Sheppard \& Ely, 2008).

A reação a todo o processo de vivência do câncer de mama pode causar um impacto que afeta não somente a mulher, mas se estende ao seu âmbito familiar e contexto social, e ainda impõe limitações na ordem física e emocional.
Esse impacto é potencializado pelos tratamentos invasivos em que o mesmo é relacionado ao término ou diminuição das atividades de lazer, de atividades domésticas, ao trabalho remunerado e aos impactos na sexualidade. Tais mudanças implicam necessidade constante de adaptação ao tratamento e ao novo estilo de vida, conforme ressaltam Romeiro, Both, Machado, Lawrenz e Castro (2012).

Diante disso, e sabendo que essas adaptações dizem respeito às interações sociais mais amplas as quais estão ancoradas em um estrato social permeado por representações compartilhadas pela sociedade, lança-se mão da Teoria das Representações Sociais para apoiar as discussões deste trabalho. As representações sociais, de modo geral, podem ser vistas como "visão de mundo" que os indivíduos ou grupos têm e empregam na forma de agir e se posicionar, mas não devem se reduzir a um simples reflexo da realidade, ela é uma organização significante. Existe uma reestruturação da realidade para integrar características objetivas do objeto representado, assim como experiências anteriores do sujeito e seu sistema de valores e normas. É esta realidade reapropriada que constitui para o indivíduo ou grupo a própria realidade (Chaves \& Silva, 2011). Assim, a representação do corpo mastectomizado pelos casais pode ser estudada a partir de dois processos: a objetivação que se refere à forma como se organizam os elementos constituintes da representação e ao caminho através do qual tais elementos adquirem materialidade; e a ancoragem que se refere ao fato de qualquer tratamento da informação exigir pontos de referência: é a partir das experiências e dos esquemas já estabelecidos que o objeto da representação é pensado; tais processos estão intimamente ligados um ou outro e são modelados devido a fatores sociais (Moscovici, 2012).

À luz da Teoria das Representações Sociais a visão do corpo entendido como um objeto representacional possui diversas implicações no modo como as pessoas enxergam a si mesmas e se relacionam com o mundo ao seu redor. No caso da amostra estudada esse corpo que é o objeto de estudo, se encontra em situação de modificação. Nesse sentido uma das implicações 
é no modo como as mulheres mastectomizadas se percebem e como os outros, no caso deste trabalho, os seus parceiros as percebem. Voltar o olhar para as representações sociais não apenas da mulher mastectomizada, mas também do seu parceiro é importante para entendermos como o casal representa a retirada do seio, órgão socialmente valorizado como identidade de feminilidade e de sexualidade e como tais representações possuem impacto na relação do casal, especificamente na satisfação sexual. Para tanto, tal pesquisa objetiva verificar quais as representações sociais compartilhadas sobre o corpo da mulher e do corpo mastectomizado para as mulheres mastectomizadas e seus parceiros e qual o nível de satisfação sexual do casal, acessando as falas e vivências destes e as ressignificações dadas a esse corpo que foi transformado. Para alcançar este objetivo foi elaborada a pesquisa descrita a seguir, tendo como fundamento a Teoria das Representações Sociais na perspectiva dimensional, a qual se caracteriza pelo estudo dos conteúdos representacionais, abarcando a totalidade de expressões, ideias, imagens e valores que circulam no discurso sobre o objeto.

\section{Método}

\section{Participantes}

Trata-se de um estudo de cunho descritivo, quanti-qualitativo, no qual participaram 10 díades (10 mulheres mastectomizadas e seus respectivos parceiros); e empregou-se amostragem não probabilística e de conveniência. Utilizaram-se como critérios de inclusão mulheres que passaram pelo procedimento de mastectomia, com ou sem reconstrução, há no mínimo 1 ano e que tinham um parceiro fixo que estava junto antes e após o procedimento. A idade média foi de 50 anos, o tempo de convivência conjugal possuiu uma média de 24 anos; $55 \%$ da amostra possui escolaridade de nível superior; em relação à atividade remunerada $90 \%$ dos homens e $60 \%$ das mulheres exerciam. Em relação à cirurgia $60 \%$ das mulheres realizaram a cirurgia de mastectomia entre 1 e 5 anos atrás, $50 \%$ delas fizeram a cirurgia de reconstrução e todas ficaram satisfeitas com o resultado, das que não realizaram a reconstrução apenas uma relatou não estar satisfeita.

\section{Instrumentos}

Objetivando-se conhecer e analisar os conteúdos representacionais atribuídos ao corpo da mulher, ao corpo da mulher mastectomizada pelas mulheres mastectomizadas e seus parceiros, utilizou-se a Técnica de Associação Livre de Palavras (TALP). Foram utilizados os estímulos indutores: "corpo da mulher" e "corpo da mulher mastectomizada" com o objetivo de estabelecer um ponto de comparação entre o corpo não modificado e o corpo mastectomizado. Também foi aplicada uma escala acerca do nível da satisfação sexual, na qual o respondente marcava de 0 a 10 o quanto ele avaliava o nível de sua satisfação sexual antes da mastectomia e após a mastectomia.

\section{Procedimentos de Coleta de Dados}

As aplicações foram realizadas em uma Organização não Governamental (ONG), em um hospital e no domicilio dos entrevistados; para composição da amostra utilizou-se o método bola de neve que consiste em um método tipicamente utilizado com populações raras, desconhecidas ou que são mais difíceis de contatar (Dewes, 2013). Após a assinatura do Termo de Consentimento Livre e Esclarecido (TCLE), aplicou-se o TALP; durante o qual era solicitado que para cada estímulo indutor narrado pelo entrevistador o participante associasse cinco palavras, num período de tempo de 1 minuto. Em seguida os participantes responderam à Escala de Satisfação Sexual.

\section{Procedimentos de Análise de Dados}

Utilizou-se a Análise Temática de Conteúdo proposta por Bardin (1977) para os dados emergidos do TALP. Esta análise busca estabelecer categorias de representação a posteriori com as palavras evocadas pelos participantes do estudo. A escolha dessa técnica se dá, primeiramente, por esta se aplicar a toda e qualquer comunicação com transferência de significados de um emissor a um receptor. Em segundo lugar, a análise de conteúdo utiliza procedimentos sistemá- 
ticos para descrever os conteúdos das mensagens e extrair deles indicadores que permitam inferir conhecimentos relativos a condições de produção dessas mensagens (Ramalho et al., 2014).

Análise de Conteúdo, pode ser definida como:

Um conjunto de técnicas de análise das comunicações visando obter, por procedimentos sistemáticos e objetivos de descrição do conteúdo das mensagens, indicadores (quantitativos ou não) que permitam a inferência de conhecimentos relativos às condições de produção/recepção (variáveis inferidas) destas mensagens. (Bardin, 1977, p. 42)

De acordo com esta definição, a Análise de Conteúdo utiliza um conjunto de técnicas parciais, porém complementares, para a sistematização e a explicação do conteúdo e do seu significado, através de deduções lógicas e bem justificadas, tendo como referência quem emitiu e o contexto ou os efeitos da mensagem (Maciel \& Melo, 2011).

Segundo Minayo (1998), existem diferentes tipos de análise de conteúdo, dentre eles a temática, a qual foi utilizada no presente estudo. A análise de conteúdo temática se propõe a codificar ou caracterizar um segmento, colocando-o em uma das classes de equivalência, determinadas a partir das significações. Essa análise funciona por etapas, abrangendo dois momentos distintos: no primeiro, ocorre o inventário ou isolamento dos elementos, sendo realizadas operações de desmembramento do texto em unidades e categorias. O segundo momento corresponde ao reagrupamento analítico, sendo feita a classificação ou organização das mensagens a partir dos elementos repartidos.

De acordo com Bardin (1977) e Vala (2003), são indicadas três operações básicas que devem constar numa análise de conteúdo. Primeiro é recomendável uma "leitura flutuante", na qual o pesquisador vai gradualmente se apropriando do texto, numa relação de idas e vindas entre suas anotações e o material analisado.

A segunda operação diz respeito à definição de categorias. Ao se analisar um documento, de- ve-se realizar a categorização e classificação dos seus conteúdos, visando a redução da sua complexidade, o que facilitará uma posterior explicação e apreensão da realidade. Normalmente, as categorias são criadas no momento da análise, de acordo com o material. Essas categorias indicam a significação central do conceito que se quer apreender e de outros indicadores que descrevem o campo semântico do conceito.

A terceira operação é a definição das unidades de análise, que são de três tipos: unidade de registro ou temática, unidade de contexto e unidade de enumeração. De acordo com Vala (2003, p. 114), "as unidades de registro são determinados segmentos de conteúdo que se caracterizam colocando-se numa dada categoria". Para Bardin (1977), a unidade de contexto contribui para a compreensão dos significados, na medida em que, além de codificar e agrupar as unidades de registro, atribui a elas um sentido engajado. Por fim, tem-se a unidade de enumeração, através da qual se realiza a quantificação da presença ou ausência de unidades no discurso.

Essas operações propiciam a classificação dos elementos conforme suas semelhanças e diferenças, com posterior reagrupamento, em função de características comuns. Também podem ser realizadas operações estatísticas, desde as mais simples, como o cálculo das frequências, até outras que usam procedimentos estatísticos complexos (Maciel \& Melo, 2011).

Como a análise de conteúdo é uma técnica de tratamento dos dados aberta às interpretações do pesquisador, pode apresentar vieses. Em função disso, recorre-se a outros pesquisadores que possuem experiência com esta técnica para que eles validem as categorias e subcategorias encontradas pelo pesquisador. Este procedimento chama-se análise dos juízes e foi realizado no presente estudo por dois pesquisadores com experiência em análise de conteúdo. Assim, foram entregues cinco entrevistas para dois juízes para que eles realizassem a análise seguindo todas as etapas necessárias. Posteriormente, compararam-se as categorias e subcategorias existentes, permanecendo aquelas presentes na análise de pelo menos dois analistas (ou os dois juízes, ou um juiz e a pesquisadora). 
Para análise de dados da Escala de Satisfação Sexual utilizou-se o Pacote Estatístico para as Ciências Sociais (SPSS) para Windows 8 versão PASW-21.0. Esta escala foi aplicada com o objetivo de descrever qual o nível de satisfação sexual na opinião das díades; por isso, optou-se por realizar estatísticas descritivas como média, desvio padrão e frequências simples.

\section{Procedimentos Éticos}

Para a execução deste estudo, foram obedecidas as determinações éticas contempladas na
Resolução $n^{\circ}$ 466/12 do Conselho Nacional de Saúde (CNS), que trata da ética em pesquisas envolvendo seres humanos, tendo sido autorizada a pesquisa com o protocolo $\mathrm{n}^{\circ}$ 0276/14.

\section{Resultados e Discussões}

A seguir serão apresentados os resultados da análise de conteúdo temática realizada a partir das evocações emergidas no TALP, aplicado com as díades. Os dados serão apresentados em termos de frequências simples em tabelas e discutidos em seguida.

Tabela 1

Categorias Representacionais dos Estímulos Corpo da Mulher e Corpo da Mulher Mastectomizada

Corpo da Mulher

\begin{tabular}{|c|c|c|}
\hline Categorias & Homens & Mulheres \\
\hline $\begin{array}{l}\text { Aparência } \\
\text { corporal }\end{array}$ & $\begin{array}{c}F=32 \\
\text { Ex: bonito, pernas, olhos, perfeição }\end{array}$ & $\begin{array}{c}F=42 \\
\text { Ex: bonito, perfeito, gordo, magro }\end{array}$ \\
\hline Afetividade & $\begin{array}{c}F=7 \\
\text { Ex: amor, bom carinho, maternidade }\end{array}$ & $\begin{array}{l}\qquad F=6 \\
\text { Ex: autoestima, identidade, coragem, cuidados }\end{array}$ \\
\hline $\begin{array}{l}\text { Elementos } \\
\text { sexuais }\end{array}$ & $\begin{array}{c}F=11 \\
\text { Ex: sexo, desejo, gostoso, satisfaz }\end{array}$ & $\begin{array}{c}F=1 \\
\text { Ex: sensualidade }\end{array}$ \\
\hline \multicolumn{3}{|c|}{ Corpo da Mulher Mastectomizada } \\
\hline Categorias & Homens & Mulheres \\
\hline $\begin{array}{l}\text { Aparência } \\
\text { corporal }\end{array}$ & $\begin{array}{c}F=21 \\
\text { Ex: falta, diferente, mesma coisa }\end{array}$ & $\begin{array}{c}F=22 \\
\text { Ex: falta, mutilação, vergonha, reconstrução }\end{array}$ \\
\hline Afetividade & $\begin{array}{c}F=24 \\
\text { Ex: pena, tristeza, difícil, preconceito }\end{array}$ & $\begin{array}{c}F=26 \\
\text { Ex: aceitação, difícil, mudança, medo }\end{array}$ \\
\hline $\begin{array}{l}\text { Elementos } \\
\text { sexuais }\end{array}$ & $\begin{array}{c}F=2 \\
\text { Ex: sexo, desejo }\end{array}$ & $F=0$ \\
\hline
\end{tabular}

Nota. O F refere-se à frequência de palavras evocadas.

Na Tabela 1 estão representados os resultados para o estímulo corpo da mulher e corpo da mulher mastectomizada. O primeiro estímulo foi utilizado com o objetivo de apreender quais as representações que as mulheres mastectomizadas e seus parceiros possuem acerca do corpo da mulher de modo geral, fazendo um comparativo com as representações do segundo estímulo corpo da mulher mastectomizada. Para ambos os estímulos surgiram na análise três (3) categorias denominadas: aparência corporal, afetividade, elementos sexuais, indicando a importância do estímulo para o casal.

Para o estímulo corpo da mulher observou-se um total de 99 evocações; destas a categoria que mais apresentou evocações foi a Aparência corporal, correspondendo a $75 \%$ do total de evocações, já a Afetividade corres- 
pondeu a $13 \%$ e os Elementos sexuais a $12 \%$ do total. Para o estímulo corpo da mulher mastectomizada este recebeu um total de 95 evocações, que também se dividiram nas categorias: Aparência corporal representou um total de 43 evocações correspondendo a $45 \%$ do total; Afetividade apresentou 50 evocações correspondendo a $52 \%$ do total, e os Elementos sexuais só apareceram para os homens correspondendo a $3 \%$ do total.

Pode-se destacar aqui uma primeira diferencial no que diz respeito às representações dos objetos estudados, onde para o corpo da mulher as representações estão mais vinculadas à aparência corporal, havendo um peso acentuado nos elementos sexuais. Já no corpo da mulher mastectomizada as representações são mais ancoradas na afetividade em primeiro lugar seguida pela aparência corporal; contudo, as diferenças também se sobressaem em relação a outras questões que serão detalhadas abaixo.

$\mathrm{Na}$ categoria Aparência Corporal, no que se refere ao estímulo "corpo da mulher" este foi representado pelas objetivações: "bonito", "perfeito", "pernas", "gordo" e "magro", que representam o aspecto físico do corpo da mulher, possuindo características positivas como a beleza e a perfeição ou características constituidoras como pernas, olhos, rosto e boca. Já as representações para o "corpo da mulher mastectomizada", no que se refere a esta categoria, foi representado por palavras como: "mutilação", "falta", "vergonha", "reconstrução" e "diferente". Aqui se nota a carga mais negativa demonstrando que o corpo mastectomizado possui um imaginário estereotipado e relacionado à perda do órgão da mama.

Todavia, as evocações vão diferir um pouco, em termos de significados entre os casais, os homens representam como "diferente", "falta", mas também representam como "mesma coisa". O parceiro tende a passar pelo processo mais rapidamente e aceitam a mudança mais fácil, conforme afirmam Salles, Cecílio, Pereira e Maia, (2012) e uma vez que convive direta e intimamente com a mulher mastectomizada, os sentimentos e experiências vividas pelos parcei- ros podem servir de base para estabelecimento de estratégias de suporte para as mulheres e suas famílias nesse processo. Os estudos com casais, de Ferreira, Farrago, Diniz dos Reis e Funghetto (2011), corroboram com os resultados encontrados; segundo eles houve um consenso entre os homens, os quais verbalizaram que não houve alterações com a retirada da mama, visto que o importante era a manutenção da vida da companheira.

As mulheres representam mais negativamente porque são atingidas diretamente pela transformação em seus corpos, o que acarreta uma alteração na imagem corporal, onde a perda da mama se traduz em sentimentos de acanhamento, inferioridade, vergonha, inibição e baixa autoestima, a mulher passa a se sentir incapaz de atuar como mulher perante a sociedade, sua família e parceiro. As mulheres mastectomizadas ao evocarem representações acerca do corpo mastectomizado, não estão de fora, mas se confundem com o objeto representado, repleto de subjetividades que atravessam todas as repercussões de ser o sujeito/objeto desse corpo marcado.

Essas representações do corpo da mulher, de perfeição e de beleza, são reflexos de uma construção social no modo de conceber o corpo feminino, exigindo sua boa forma. Tais elementos são compartilhados socialmente e influem na autoestima das mulheres que passam por alterações no corpo (Salles et al., 2012; Siqueira \& Faria, 2007).

Já na categoria Afetividade para o estímulo "corpo da mulher", ambos os atores sociais objetivaram como: "amor", "carinho", "bom", "autoestima". No entanto, ambos diferem em algumas palavras; podemos perceber que para os homens há a questão do carinho, maternidade e amor, denotando a visão de que os parceiros compreendem as mulheres como cuidadoras, maternais e amorosas, representações estas ligadas à mulher e compartilhadas socialmente. Já as mulheres evocaram questões voltadas para a autoestima, identidade, cuidados, o que denota uma preocupação com o seu corpo como determinante de sua autoestima e identidade. 
No que diz respeito às representações para o "corpo da mulher mastectomizada" surge a Afetividade, tanto para os homens como para as mulheres e esta foi objetivada por palavras como: "pena", "difícil", "tristeza", "preconceito", "aceitação", "mudança". Essas palavras denotam que o estímulo apresentado reporta a representações de cunho afetivo, ligado a sentimentos como tristeza, mas também como aceitação. Percebe-se nessa categoria que o corpo da mulher mastectomizada foi objetivado de forma mais negativa em relação às representações acerca do corpo da mulher (Tabela 1). Aqui se percebe que a afetividade é ligada às questões voltadas para a penalização. Esse corpo passa a ser representado como um corpo rejeitado e foco de preconceito; esses sentimentos contribuem no comprometimento da autoimagem dessas mulheres e até exclusão social das mesmas (Ibiapina et al., 2015).

$\mathrm{Na}$ categoria Elementos sexuais evidencia-se a diferença entre homens e mulheres para ambos os estímulos "corpo da mulher" e "corpo da mulher mastectomizada", havendo destaque para os homens. Essa categoria apresentou objetivações como: "desejo", "sexo", "gostoso", "satisfaz", ancorando-se no imaginário relacionado ao corpo da mulher como objeto de desejo ou como símbolo sexual. Tais representações do corpo feminino são apresentadas pela mídia em geral, de forma cosmetizada, fetichizada, impregnada de conotações eróticas, sedutoras, sexuais, sensoriais e sensuais, a exemplo das propagandas dirigidas aos homens onde há o reforçamento da mulher como símbolo sexual ligado a produtos considerados como fonte de desejo ou status para os homens (Souza, Oliveira, Nascimento, \& Carvalho, 2013).

Desse modo, as imagens midiáticas do corpo feminino ao serem propagadas de forma estereotipada pelos meios de comunicação formal e informal formam uma padronização do corpo que confirma o culto ao corpo, na medida em que também apontam um problema no campo da saúde, visto que as mulheres são alcançadas pela impossibilidade de não alcançar o corpo desejado, perfeito e cultuado pelo imaginário midiático (Sá-Serafim, 2013).

Logo, deixa uma preocupação com relação à sexualidade das mulheres acometidas pelo câncer de mama e mastectomia, pois as mesmas não expressam conteúdos de sexualidade vinculados ao corpo, o que pode interferir diretamente na sexualidade e na relação conjugal. Uma das funções das representações sociais é a de orientação que se refere às representações como guia dos comportamentos e das práticas sociais. Constitui-se em um sistema de pré-codificação da realidade, um guia para a ação. Além disso, as representações sociais também permitem, a posteriori, justificar comportamentos e tomadas de posição (Chaves \& Silva, 2011). Diante disto, as representações relacionadas ao corpo mastectomizado, tanto para mulheres como para seus parceiros podem gerar mudanças em suas condutas e uma delas é no exercer de sua sexualidade.

Na tentativa de analisar a percepção dos casais acerca do impacto da mastectomia na sexualidade do casal serão apresentados os dados da escala de satisfação sexual, na Tabela 2 frequências simples.

Tabela 2

Nível de Satisfação Sexual das Díades Antes e Após a Mastectomia

\begin{tabular}{ccccccccccccc}
\hline Itens & 7 & 8 & 9 & 10 & $M$ & 4 & 5 & 7 & 8 & 9 & 10 & $M$ \\
\hline Homens & 1 & - & 3 & 6 & 9,4 & 1 & 2 & 1 & - & 3 & 3 & 7,8 \\
Mulheres & - & 2 & 2 & 6 & 9,4 & - & 3 & 2 & 3 & - & 2 & 7,3 \\
\hline
\end{tabular}

Nota. O M se refere à média de satisfação sexual descrita pelos participantes numa escala de 0 a 10, antes e depois da cirurgia da mastectomia. 
Em relação ao nível de satisfação sexual os casais apontam uma diminuição na satisfação sexual pós-mastectomia. As classificações de 7 , 8,9 e 10 foram as que registraram maior percentagem para a satisfação sexual antes da cirurgia, indicando que os participantes da amostra classificam a sua satisfação sexual antes da cirurgia entre boa e ótima. Já a satisfação sexual depois da mastectomia obteve um maior espectro de classificações, variando entre 4, 5, 7, 8, 9 e 10, indicando que a satisfação sexual depois da cirurgia foi relatada com um decréscimo para alguns casais. A média de satisfação sexual antes da cirurgia, para ambos os sexos foi de 9,4 com desvio padrão de 0,51 . Já a média de satisfação sexual depois da cirurgia foi de 7,5 e desvio padrão de 2,08. No entanto, a média de satisfação sexual depois da cirurgia para as mulheres foi um pouco menor em relação aos homens, como visto na Tabela 2.

Alguns estudos corroboram com esses achados como o de Santos et al. (2008) que procuraram avaliar a satisfação da relação sexual antes e depois do câncer de mama e afirmam que após a incidência da doença as mulheres notaram uma diminuição da procura do companheiro por sexo e, por conseguinte, da frequência das relações. Além disso, as participantes afirmaram que antes da doença o relacionamento sexual com o companheiro era muito bom, com as relações sendo satisfatórias e ocorrendo com frequência. Na literatura não existe um padrão de reações do parceiro na retomada da vida sexual após o câncer e a mastectomia, alguns deles se afastam e outros se tornam ainda mais carinhosos e atenciosos para com as parceiras. Muitas mulheres temem a não aceitação pelo parceiro de sua nova condição, o que pode dever-se à associação feita por tais mulheres entre sexualidade e genitalidade, $o$ que as leva a pensar que a ausência das mamas tende a provocar necessariamente um distanciamento do companheiro, pois sua imagem corporal aparece modificada (Santos et al., 2008).

Speer et al. (2005) em seu estudo com mulheres mastectomizadas, no qual foram comparadas mulheres com câncer de mama, mulheres com disfunção sexual e mulheres da população geral, as participantes com câncer de mama apresentaram escores significativamente piores em todas as áreas do funcionamento sexual (desejo, excitação, lubrificação, orgasmo, satisfação e dor) em comparação com o grupo controle normal, porém apresentaram um melhor funcionamento do que o apresentado pelas mulheres com disfunção sexual em todas as áreas, exceto desejo sexual e dor. Além dos fatores físicos citados anteriormente, há ainda o fato de a imagem corporal abalada das mulheres interferir no modo como o casal se relaciona sexualmente. Nos estudos de Sheppard e Elly (2008), estes constataram que há um prejuízo sexual nos casais devido à dificuldade de enfrentar a situação do câncer de mama; alguns casais acabam chegando à separação, pois alguns parceiros não conseguem enfrentar a situação, mas em contrapartida há também o prejuízo da satisfação sexual porque as mulheres percebem indevidamente seus parceiros, acreditando que eles estão desinteressados e irão rejeitá-las devido à aparência corporal e assim elas acabam por afastar-se emocional e sexualmente.

Como se pode observar, o câncer de mama provoca uma série de mudanças na vida das mulheres, interferindo no sentimento em relação a si mesmo e na percepção da vida; emergem sentimentos contraditórios de esperança na cura e medo de recidiva, de enfrentar a mutilação imposta pela mastectomia, associado a preocupações com a feminilidade e com as reações do companheiro frente à mastectomia, o que pode acarretar em uma baixa autoestima (Salles et al., 2012). Associado a isto a reação do parceiro está diretamente vinculada ao restabelecimento, à recuperação da identidade corporal e sexual, de modo que a importância do apoio à mulher com câncer de mama pode ser observada em estudo em que se verificou que mulheres com companheiro apresentaram melhora nas suas emoções e no relacionamento interpessoal (Ferreira et al., 2011).

Baseado em tais achados, no que ocorre com as mulheres mastectomizadas e seus parceiros, compreendendo as representações que elas mesmas elaboram e seus parceiros acerca do corpo e do corpo mastectomizado e da satisfação sexual, foi de extrema importância para compre- 
ensão das vivências e das repercussões que essas representações podem gerar na vida dessas mulheres e de seus parceiros, no que se refere às representações corporais e sua implicação na sexualidade.

\section{Considerações Finais}

De modo geral, observou-se que há diferenças entre as representações do corpo da mulher e do corpo da mulher mastectomizada, onde o corpo da mulher foi objetivado pela díade como perfeito, bonito e sexual. Essas representações são ancoradas no imaginário social construído acerca do corpo da mulher como sensual, feminino, perfeito e livre de defeitos. Já o corpo da mulher mastectomizada foi objetivado como falta, feio, mutilado e triste. Essas representações são ancoradas também na noção de que o corpo da mulher deve ser saudável e perfeito; além disso, esse corpo foi portador de uma doença estigmatizada que é o câncer. Observou-se que há uma diminuição na satisfação sexual do casal. No entanto, a satisfação sexual ainda é considerada boa, pois o casal procura criar estratégias para conviver com a falta da mama e suas repercussões; além disso, o suporte social que os parceiros oferecem é um fator de enfrentamento e aceitação.

Há, ainda, poucos estudos que abordam a vivência do casal frente ao câncer de mama feminino, havendo necessidade de outras pesquisas que facilitem a compreensão de tal situação, visto que, na maioria dos estudos, a preocupação é conhecer as repercussões existentes na vida da mulher, deixando de lado a opinião e reação do companheiro que se depara e vivencia todos os estágios da doença. Além disso, as mulheres remetem a mastectomia ao preconceito, à vergonha e ao medo de se expor com as cicatrizes e à falta da mama para outras pessoas. Esse estudo lança para futuros estudos a necessidade de estudar mais a fundo os aspectos relacionados ao preconceito em relação à mulher mastectomizada.

Acredita-se que o presente estudo tenha sido propulsor de reflexões acerca da temática que envolve as mulheres mastectomizadas e seus parceiros em relação às representações do corpo mastectomizado e à satisfação sexual do casal, possibilitando o despertar de estratégias de cuidado e enfrentamento da doença e recuperação da integridade, da autoestima e da autoimagem dessas mulheres. É necessário também que os profissionais de saúde e da assistência que prestam serviços a essa população criem planos de intervenção e grupos de diálogo, buscando proporcionar mais informação e estratégias de atendimento que promovam a superação das implicações psicológicas, emocionais e sociais acarretadas pela mastectomia e o câncer de mama.

\section{Referências}

Angerami, V. A. (2013) A subjetivação do câncer. In V. A. Angerami-Camon \& K. C. Gaspar (Eds.), Psicologia e câncer. São Paulo, SP: Casa do Psicólogo.

Bardin, L. (1977). Análise de conteúdo. São Paulo, SP: Martins Fontes.

Cesnik, V. M., \& Santos, M. A (2012). Desconfortos físicos decorrentes dos tratamentos do câncer de mama influenciam a sexualidade da mulher mastectomizada. Revista da Escola de Enfermagem USP, 46(4), 1001-8. Recuperado em www. ee.usp.br/reeusp/

Chaves, A. M., \& Silva P. (2011). Representações Sociais. In L. Camino, A. R. R. Torres, M. E. O. Lima \& M. E. Pereira. (Eds.), Psicologia Social: Temas e teorias (p. 636). Brasília, DF: Technopolitik.

Dewes, J. O. (2013). Amostragem em Bola de neve e respondent-driven simpling: Uma descrição de métodos (Monografia). Departamento de Estatística. Universidade do Rio Grande do Sul, Porto Alegre, RS, Brasil.

Ferreira, D. B., Farrago, P. M., Diniz dos Reis, P. E., \& Funghetto, S. S. (2011). Nossa vida após o câncer de mama: Percepções e repercussões sob o olhar do casal. Revista Brasileira de Enfermagem, 64(3), 536-44. Recuperado em http://www. scielo.br/pdf/reben/v64n3/v64n3a18.pdf

Ibiapina, A R. S., Maia, J. M., Silva, L. D. C., Fernandes, M. A., Filho, A. A. I. C. \& Fernandes, R. O. (2015). Aspectos psicoemocionais de mulheres pós-mastectomizadas participantes de um grupo de apoio de um hospital geral. Revista Interdisciplinar, 8(3), 135-142. 
Instituto Nacional de Câncer. (2014). Incidência do Câncer no Brasil. Rio de Janeiro, RJ: Autor. Recuperado em http://www2.inca.gov.br/wps/ $\mathrm{wcm} /$ connect/acoes_programas/site/home/nobrasil/programa_controle_cancer_mama/conceito magnitude

Maciel, S. C., \& Melo, J. R. F. (2011). O recurso da entrevista e da análise de conteúdo em pesquisas qualitativas. In M. P. L. Coutinho \& E. R. A. Saraiva (Eds.), Métodos de pesquisa em Psicologia Social, perspectivas qualitativas e quantitativas (pp. 175-204). João Pessoa, PB: Editora Universitária.

Minayo, M. C. S. (1998). O desafio do conhecimento: Pesquisa qualitativa em saúde (5. ed.). São Paulo, SP: Hucitec-Abrasco.

Moscovici, S. (2012). A Psicanálise, sua imagem e seu público (S. Fuhrmann, Trad.). Petrópolis, RJ: Vozes.

Ramalho, T. M. M., Maciel, S. C., Medeiros, K. T., Souza, G. L. S., Cruz, L. F. P., \& Nascimento, R. P. F. (2014). Representações sociais sobre a loucura: Intervenções inclusivas com estudantes de ensino médio. In S. C. Maciel, W. C. G. Di Lourenzo Lima, \& S. F. O. Andrade (Eds.), Saúde Mental e Dependência Química. João Pessoa, PB: Universidade Federal da Paraíba.

Romeiro, F. B., Both, L. M., Machado, A. C. A., Lawrenz, P., \& Castro, E. K. (2012). O apoio social das mulheres com câncer de mama: Revisão de artigos científicos brasileiros. Revista Psicologia e Saúde, 4(1), 27-38. Recuperado em http:// www.gpec.ucdb.br/pssa/index.php/pssa/article/viewFile/122/209

Salles, J. B., Cecilio, S. G., Pereira, N. P. A., \& Maia, L. L. Q G. N. (2012). O convívio com a mulher mastectomizada sob a óptica do companheiro. Revista de Enfermagem do Centro Oeste Mineiro, 2(1), 10-18. doi:http://dx.doi.org/10.19175/ recom.v0i0.163

Santos, D. B., \& Vieira. E. M. (2011). Imagem corporal de mulheres com câncer de mama: Uma revisão sistemática da literatura, Ciência \& Saúde Coletiva, 16(5), 2511-2522. Recuperado em http://www.producao.usp.br/bitstream/ handle/BDPI/7756/art_SANTOS_Imagem_corporal_de_mulheres_com_cancer_de_2011. pdf? sequence $=1$

Santos, D. B. (2012). Sexualidade e imagem corporal de mulheres com câncer de mama (Tese de doutorado, Universidade de São Paulo, Ribeirão Preto, SP, Brasil).

Santos, L. N., Dias, C. A. D. C. A., Lacerda, G. L., Barreto, W. W. P., \& Rodrigues dos Santos, T. (2008). Sexualidade e câncer de mama: Relatos de oito mulheres afetadas. Psicologia Hospitalar, 6(2), 2-19. Recuperado em http://pepsic. bvsalud.org/pdf/ph/v6n2/v6n2a02.pdf

Sá-Serafim, R. C. N. (2013). Corpo mastectomizado e representações sociais: Rede de significações que conduzem a ação (Tese de doutorado, Universidade Federal da Paraíba, João Pessoa, PB, Brasil)

Scorsolini-Comin, F., dos Santos, M. A., \& Souza, L. V. (2009). Vivências e discursos de mulheres mastectomizadas: Negociações e desafios do câncer de mama. Estudos de Psicologia (Natal), 14(1), 41-50. doi:http://dx.doi.org/10.1590/ S1413-294X2009000100006

Seara, L. S., Vieira, R. X., \& Pechorro, P. S. (2012). Função sexual e imagem corporal da mulher mastectomizada. Revista Internacional de Andrología, 10(1), 104-110.

Sheppard, L. A., \& Ely, S. (2008). Breast Cancer and Sexuality. The Breast Journal, 14(2), 176181. Retrieved from http://onlinelibrary.wiley. com/doi/10.1111/j.1524-4741.2007.00550.x/ abstract

Silva, S. E. D., Vasconcelos, E. V., Santana, M. E., Araújo, J. F., Valente, J., Oliveira, J. B., Cunha, N. M. F., \& Conceição, V. M. (2012). Câncer de mama uma doença temida: Representações sociais de mulheres mastectomizadas. Revista Eletrônica Gestão \& Saúde, 3(2), 731-742. Recuperado em gestaoesaude.unb.br/index.php/ gestaoesaude/article/download/.../pdf_1

Siqueira, D. C. O., \& Faria, A. A. (2007). Corpo, saúde e beleza: Representações sociais nas revistas femininas. Comunicação, Mídia e Consumo (São Paulo), 4(9), 171-188. Recuperado em http://revistacmc.espm.br/index.php/revistacmc/article/view/95

Souza, M. R. R., Oliveira, J. F., Nascimento, E. R., \& Carvalho, E. S. S. (2013). Droga de corpo! Imagens e representações do corpo feminino em revistas brasileiras. Revista Gaúcha de Enfermagem, 34(2). doi:http://dx.doi.org/10.1590/ S1983-14472013000200008

Speer, J. J., Hillenberg, B., Sugrue, D. P., Kresge, C. L., Decker, V. B., Zakalik, D., \& Decker, D. 
A. (2005). Study of sexual functioning determinants in breast cancer survivors. The Breast Journal, 11(6), 440-447. Retrieved from http:// onlinelibrary.wiley.com/doi/10.1111/j.1075122X.2005.00131.X/abstract

Vala, J. (2003). A análise de conteúdo. In A. S. Silva \& J. M. Pinto (Eds.), Metodologia das ciências

Recebido: 24/11/2016 sociais (12. ed., pp. 101-128). Lisboa: Aponta$1^{a}$ revisão: 02/03/2017 mentos.

Aceite final: 21/03/2017

(C) O(s) autor(es), 2018. Acesso aberto. Este artigo está distribuído nos termos da Licença Internacional Creative Commons Atribuição 4.0 (http://creativecommons.org/licenses/by/4.0/), que permite o uso, distribuição e reprodução sem restrições em qualquer meio, desde que você dê crédito apropriado ao(s) autor(es) original(ais) e à fonte, fornecer um link para a licença Creative Commons e indicar se as alterações foram feitas. 